\title{
Electroencephalographic and Convulsive Effects of Binge Doses of (+)- Methamphetamine, 5-methoxydiisopropyltryptamine, and $( \pm)-3,4-$ Methylenedioxymethamphetamine in Rats
}

\author{
Devon L. Graham ${ }^{1,2,}$, Nicole R. Herring ${ }^{1,2, \#}$, Tori L. Schaefer ${ }^{1,2,}$, Katherine D. Holland ${ }^{1,2}$, \\ Charles V. Vorhees ${ }^{*}, 1,2$ and Michael T. Williams ${ }^{*}, 1,2$ \\ ${ }^{I}$ Division of Neurology, Cincinnati Children's Research Foundation, Cincinnati, OH, USA \\ ${ }^{2}$ Department of Pediatrics, University of Cincinnati College of Medicine, Cincinnati, OH, USA
}

\begin{abstract}
The abuse of drugs such as methamphetamine (MA), 3,4-methylenedioxymethamphetamine (Ecstasy, MDMA), and 5-methoxydiisopropyltryptamine (5-MeO-DIPT; Foxy) is global. Symptoms from taking these drugs include tachycardia, agitation, hyperpyrexia, and sometimes seizures. We compared the EEG effects of these drugs in male Sprague-Dawley rats ( $\sim 300 \mathrm{~g})$ implanted with cortical electroencephalographic (EEG) electrodes prior to testing. Animals received four subcutaneous injections of MA, MDMA, or Foxy $(10 \mathrm{mg} / \mathrm{kg}$ each as freebase, administered every 2 h), or saline as these doses produce lasting effects on learning, memory, and monoamines. EEG tracings were recorded before, during, and after treatment. Animals receiving MDMA showed no significant EEG abnormalities or myoclonus. MA treatment resulted in myoclonic activity and in brief $(<10 \mathrm{~s})$ EEG epileptiform activity in $\sim 50 \%$ of the rats. Longer seizure activity (10 s to $5 \mathrm{~min}$ ) was recorded in some MA-treated rats following the third and fourth doses. The onset of myoclonic activity following Foxy treatment occurred shortly after the first dose. All rats receiving Foxy showed seizures by the second dose and this continued throughout the treatment regimen. EEG abnormalities are observed after MA but not after MDMA binge dosing, which mimic the neurochemical changes seen in chronic users. While the neurochemical effects of Foxy are not known in humans, this drug causes severe EEG abnormalities and overt seizures in $100 \%$ of animals tested.
\end{abstract}

Keywords: Electroencephalographic activity, Foxy, MDMA, Methamphetamine, myoclonus.

\section{INTRODUCTION}

Among the symptoms associated with illicit drug use are seizures and/or abnormal electroencephalograms (EEG) [16] after use of methamphetamine (MA) and 3,4methylenedioxymethamphetamine (MDMA). Studies have shown that abstinent MA users exhibit abnormal EEGs as well as higher power delta and theta wave (slow wave) activity [7] with psychomotor slowing. The increased theta quantitative EEG power was correlated with decreased reaction times in complex tasks and diminished accuracy on the N-back working memory task [8]. Others have shown that increased theta power (slow wave) in abstinent MA users is correlated with deficits in performance on verbal and

*Address correspondence to these authors at the Division of Neurology MLC 7044, Cincinnati Children's Research Foundation 3333 Burnet Ave, Cincinnati, OH 45229-3039, USA; Tel: (513) 636-8624, (513) 636-8622; Fax: (513) 636-3912; E-mails: michael.williams@cchmc.org, charles.vorhees@cchmc.org

PPresent address: Department of Pharmacology, Vanderbilt University School of Medicine, 23rd Ave South; 476 RRB; Nashville TN 37232-6600, USA

"Present address: Department of Anatomical Sciences and Neurobiology, University of Louisville School of Medicine, 500 South Preston St., Louisville, KY 40202, USA nonverbal learning and memory tests [9] and other symptoms (hypertension, elevated heart and respiratory rates, and hallucinations) [1, 10]. While MA-induced seizures are typically transient, there are cases showing status epilepticus [1]. High doses of MA and amphetamine elicit status epilepticus and myoclonus in mice [11] and rats [12]. In mice, seizure onset following intraventricular MA treatment is prolonged and MA-induced seizures are treatment-resistant [13].

MDMA use results in decreased EEG synchrony (coherence) [14-16]. Increases in alpha and beta power among MDMA users are also seen [14]. Increases in alpha waves are inversely correlated with mental activity $[17,18]$, while elevated beta wave activity is associated with depression [19] and stress/anxiety [20]. Abnormal EEGs following MDMA use have been reported [6, 21], including seizures [22-24]. While many of the cases suggest that druginduced seizures are transient $[1,25]$, they are associated with long-term neurocognitive abnormalities [8, 26]. Fornai and colleagues found that exposing mice to MDMA resulted in EEG slowing [27, 28], increased susceptibility to seizure onset following kainic acid [28], and latent limbic hyperexcitability ([28]; however, see [27]). There was no evidence of spontaneous seizures resulting from MDMA. 
While abnormal EEG activity and seizures are known to occur following MA and MDMA abuse in humans, little is known about seizure risk from 5-methoxy-n,ndiisopropyltryptamine (Foxy). Foxy is a newer club drug with hallucinogenic properties. There are reports of users having seizures [29, 30], but it is not clear if these are attributable to interactions with other factors. We found that approximately half of Foxy-treated animals displayed seizure-like behavior [31]. The purpose of the present experiment was to compare the EEG profile of these three psychostimulants using a dose we have used in previous experiments that induced long-term learning and memory deficits and/or neurochemical changes. Specifically, the dose of MA has been shown to induce monoamine deficits [3243], elevated glial fibrillary acidic protein [44, 45], and deficits in learning and memory [46, 47]. Using interspecies scaling [48], a $10 \mathrm{mg} / \mathrm{kg}$ administration of MA in rats is equivalent to that used by a MA user taking approximately 1 $\mathrm{mg} / \mathrm{kg}$ [49], which is within the range of what drug users are known to take [50]. This same dose of MDMA has been shown to be both well-tolerated in rodents as well as causing reductions and other alterations in the serotonergic system [51-54], elevated anxiety [54,55], changes in locomotor activity $[54,56,57]$, and deficits in learning [56, 58] and memory [56]. Few studies have investigated the effects of Foxy. We have shown that a single dose of $20 \mathrm{mg} / \mathrm{kg}$ induces alterations in glucose and an elevated stress response during development and adulthood [59], while multiple doses of 10 or $20 \mathrm{mg} / \mathrm{kg}$ elicits elevated corticosterone and spatial learning deficits in adults [31]. In other studies where Foxy is administered to adolescent rats (P35-48, $6 \times 5-20$ $\mathrm{mg} / \mathrm{kg} / 48 \mathrm{~h}$ ), spatial learning and serotonergic deficits were demonstrated [60, 61]. Furthermore, daily doses $(4 \times 10$ $\mathrm{mg} / \mathrm{kg} / 2 \mathrm{~h}$ ) during development results in long-term deficits in learning and increased anxiety [62]. We hypothesized that all three drugs would induce EEG abnormalities similar to those described in humans.

\section{MATERIALS AND METHODS}

\section{Animals}

Male Sprague-Dawley CD (IGS) rats (225-250 g, Charles River Laboratories, Raleigh, NC) were habituated for at least 1 week and doubly housed in a vivarium controlled for temperature $\left(19 \pm 1^{\circ} \mathrm{C}\right)$ and humidity $(50 \% \pm 10 \%)$. Animals were maintained on a $14 \mathrm{~h}$ light: $10 \mathrm{~h}$ dark cycle, and food and water were available ad libitum. Temperature transponders were implanted 3 days prior to surgery. All animal procedures were approved by the Institutional Animal Care and Use Committee of Cincinnati Children's Research Foundation.

\section{Surgical Procedures}

All procedures were performed under sterile conditions using isoflurane anesthesia (IsoThesia; Butler Animal Health Supply, Dublin $\mathrm{OH})$. Rats were initially anesthetized by placing them in an airtight chamber and isoflurane (4-5\%) vapor was infused into the chamber until the animal was unresponsive. The rat was then removed and anesthesia maintained using a gas anesthesia mask adaptor (Harvard Apparatus, Holliston, MA) connected to a Datex Ohmeda
Excel 210 SE (Soma Technology, Inc., Bloomfield, CT) for continuous flow of isoflurane $(2-2.5 \%)$ for a duration of less than $1 \mathrm{~h}$. Depth of anesthesia was assured by the absence of corneal and pedal reflexes. An insulated wire electrode ( $0.125 \mathrm{~mm}$ diameter) was implanted stereotaxically into the left posterior hippocampus (-3.6 mm AP, $4.9 \mathrm{~mm}$; lateral, $5.0 \mathrm{~mm}$ deep with incisor bar at +5.0$)$ as described previously [63], with three additional screw electrodes implanted into the parietal cortex and two in the frontal cortex to serve as cortical, ground, and reference electrodes. Surgical adhesive and dental cement secured the electrodes in place and were used to stabilize the electrode housing unit implanted on top of the head. All animals received an injection of the analgesic Buprenex during recovery. The hippocampal electrode was a polymide-insulated stainless steel wire $(0.2 \mathrm{~mm}$ diameter, cut to $2 \mathrm{~cm}$ length (Plastics One Inc., Roanoke, VA)) and the end inserted into the brain was sanded to expose the wire, while the cortical electrodes were Teflon-coated stainless steel electrodes without sockets [20 $\mathrm{mm}$ length electrode with a screw size of $0-80 \times 1 / 8,3.2 \mathrm{~mm}$ length (Plastics One)]. All electrodes were soldered to a tinplated brass Molex connector (Jameco Electronics, Belmont, $\mathrm{CA}$ ), and conductance was tested prior to the experiment using a multimeter. Electrodes with the connectors were inserted following implantation into a 4-position Molex female connector housing unit (Jameco Electronics).

\section{EEG Recordings and Drug Administration}

The following day, animals were briefly exposed to isoflurane $(2.5 \%)$ in order to attach the electrodes to the EEG machine (see below) using commercially available cables (Plastics One). Animals were placed in plastic bins $(28 \mathrm{~cm} \times$ $18 \mathrm{~cm} \times 37 \mathrm{~cm})$ such that the recording device could be secured above them. The rats were allowed to move freely throughout the recording phase. EEG was recorded in awake and unrestrained rats for $475 \mathrm{~min}$. A $30 \mathrm{~min}$ baseline EEG was recorded from each rat prior to drug injection, and recordings continued for $\sim 2 \mathrm{~h}$ after the final injection. Foxy, MA, or MDMA $(4 \times 10 \mathrm{mg} / \mathrm{kg} / 2 \mathrm{~h}$ interval $)$, or an equivalent volume of saline (SAL), was administered (s.c.) after the initial baseline reading $(\mathrm{N}=4-8 /$ treatment group).

Seizures were defined as a sudden onset of high amplitude ( $>2 \mathrm{x}$ background) synchronized activity with signal progression (a change in amplitude and frequency over the course of the event) and a duration greater than $10 \mathrm{~s}$. Myoclonic activity was identified by visual observation of an isolated brief sudden jerk of the body which was accompanied by a polyspike and wave discharge on the EEG.

Temperatures were taken every $30 \mathrm{~min}$ to monitor hyperthermia. No animals had body temperatures over $40^{\circ} \mathrm{C}$ at any time point. EEG data were recorded and saved digitally using a commercially available 32-channel EEG machine and Easy EEG II software V. 1.5 (Cadwell Laboratories, Kennewick, WA) and later analyzed with filters at $1 \mathrm{~Hz}$ and $70 \mathrm{~Hz} ; 7-15 \mu \mathrm{V}$ per mm. Up to three animals were injected sequentially and EEG recorded simultaneously and continuously. After each recording session, the entire EEG record was inspected for interictal epileptiform activity seizures by a clinically-qualified 
electroencephalographer $(\mathrm{KDH})$ blinded to treatment group. The EEG recordings were scored every 5 min as follows: $0=$ normal; 1 = isolated interictal epileptiform discharges; $2=$ rhythmic bursts of epileptiform discharge lasting $<10 \mathrm{~s} ; 3=$ electrographic seizures (between $10 \mathrm{~s}$ and $5 \mathrm{~min}$ in duration); $4=$ continuous electrographic seizures $(>5 \mathrm{~min})$ or discrete electrographic seizures separated by continuous paroxysmal epileptiform discharges; $5=$ status epilepticus and death. Only intervals that were available or clear and decipherable (i.e., did not have high background, missing data due to a briefly disconnected cable, etc.) were included in the analysis. Representative EEGs of the seizures observed are shown in Fig. (1). The presence of myoclonic activity was recorded, and this activity could co-occur with EEG epileptiform activity.

\section{Statistical Analysis}

Data were analyzed using SAS Software (SAS Institute, v9.2, Cary, NC). One-way analysis of variance (ANOVA) using Proc Mixed procedure was utilized for the latency to first seizure. In cases where no seizure activity occurred, a maximum latency of $475 \mathrm{~min}$ was assigned. Fisher's test for uncorrelated proportions was used to determine the frequency of seizure types (i.e., the number of incidences of each seizure type/number of analyzed time intervals per treatment). Significance was set at $p \leq 0.05$, and data are presented as means $\pm \mathrm{SEM}$.

\section{RESULTS}

\section{Proportion of Animals Affected}

The number of animals exhibiting EEG abnormalities or myoclonic seizures were as follows: 0/4 SAL $(0 \%) ; 1 / 7$ MDMA (14.3\%), 3/8 MA (37.5\%), and 9/9 Foxy (100\%).

\section{Frequency of Seizure Activity}

The frequency of each seizure type was calculated for each subject by determining the number of incidences of each type over the total number of intervals (Table 1). SALand MDMA-treated rats did not exhibit evidence of myoclonus, while MA had significantly greater occurrences of myoclonus than SAL or MDMA (Table 1). Foxy resulted in the greatest number of incidences of myoclonus, significantly greater than all other treatments. Both Foxy and MA treatments resulted in significantly more occurrences of Type 1 (isolated spikes), 2 (epileptiform discharges $<10 \mathrm{~s}$ ), 3 (seizures between $10 \mathrm{~s}-5 \mathrm{~min}$ ), and 4 (continuous seizures $>5 \mathrm{~min}$ ) seizures than MDMA or SAL. Although MDMA administration resulted in a single Type 3 seizure, this did not result in a significant change in frequency relative to SAL treatment.

\section{Latency to First Seizure Event}

There was a significant main effect of Treatment for latency to first myoclonic event $(F(3,24)=3.01, p \leq 0.05)$, such that Foxy-treated rats exhibited evidence of myoclonus whereas no evidence of myoclonus was noted for SAL- or MDMA-treated rats, (Fig. 2a). There was a trend $(\mathrm{p}<0.10)$ for latency to be significant between MA and MDMA as well since some MA-treated animals showed a myoclonic episode. In terms of non-myoclonic seizure activity, there was a Treatment main effect $[(F(3,24)=23.85, p<0.0001)$, Fig. 2b]. Foxy-treated rats developed epileptiform activity significantly sooner than MA-, or MDMA-treated rats, and

Baseline ("0")

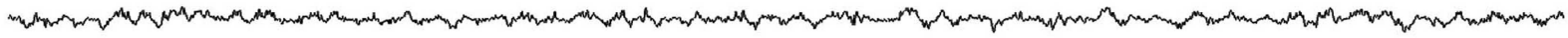

Isolated Interictal Spikes ("1")

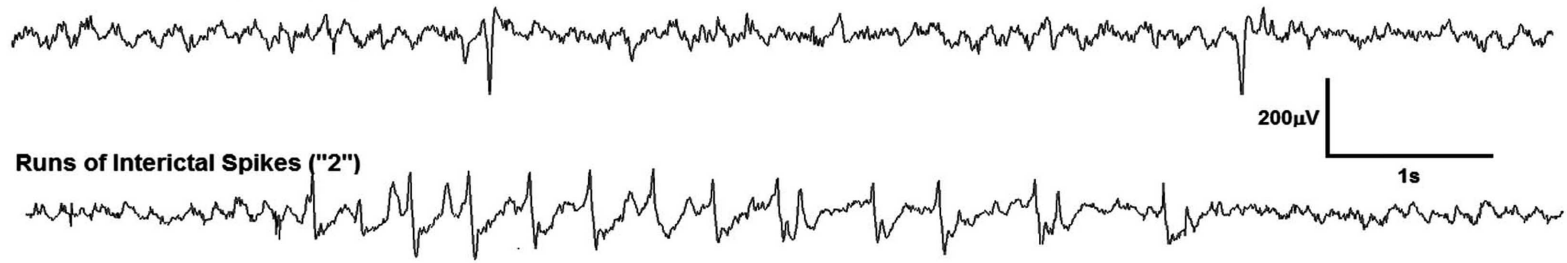

Electrographic Seizures ("3" and "4")

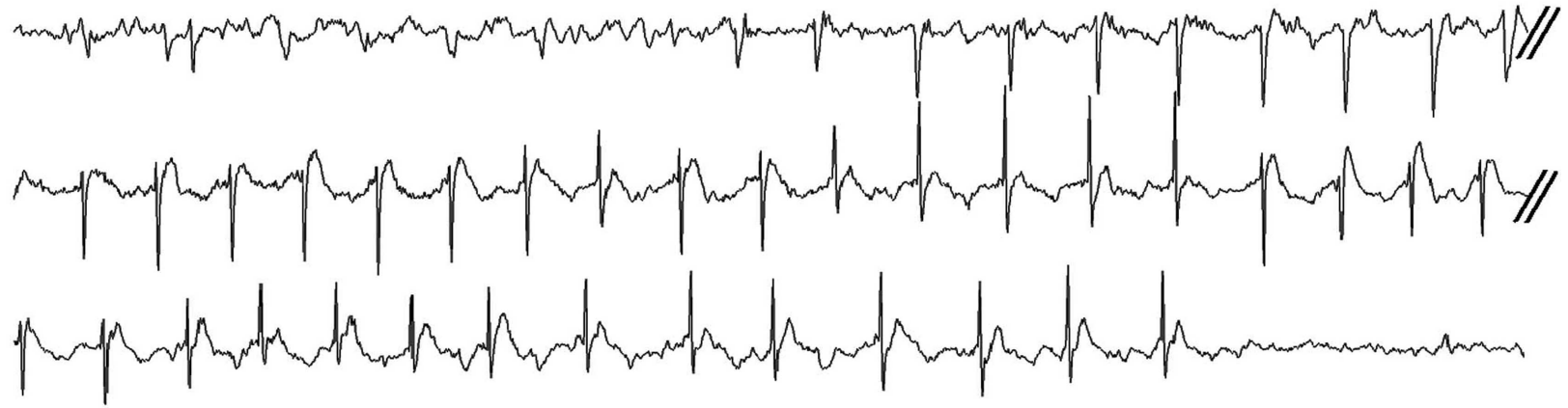

Fig. (1). Representative electrographs of EEG activity. The designations are as follows: normal activity (Type 0), isolated spikes (Type 1), runs of spikes $<10 \mathrm{~s}$ (Type 2), and continuous runs of spikes (10 s-5 min, Type 3; $>5 \mathrm{~min}$, Type 4). 
Table 1. Frequency of Seizure Type Following Drug Treatment. Values are Expressed as Total Percent of Time Spent in the Respective Seizure State: The Raw Values (Total Number of Intervals in State/Total Number of Intervals Analyzed) are Expressed Below in Parentheses. *p $<0.05,{ }^{* *}$ p $<0.01$ vs. SAL; \#p $<0.05, \#$, $<0.01$ vs MDMA; + p $<0.05,++p<0.01$ vs MA

\begin{tabular}{|c|c|c|c|c|c|}
\hline & \multicolumn{5}{|c|}{ Seizure Type } \\
\hline & Myoclonus & Type 1 & Type 2 & Type 3 & Type 4 \\
\hline SAL & $\begin{array}{c}0 \% \\
(0 / 328)\end{array}$ & $\begin{array}{c}0 \% \\
(0 / 328)\end{array}$ & $\begin{array}{c}0 \% \\
(0 / 328)\end{array}$ & $\begin{array}{c}0 \% \\
(0 / 328)\end{array}$ & $\begin{array}{c}0 \% \\
(0 / 328)\end{array}$ \\
\hline MDMA & $\begin{array}{c}0 \% \\
(0 / 565)\end{array}$ & $\begin{array}{c}0 \% \\
(0 / 565)\end{array}$ & $\begin{array}{c}0 \% \\
(0 / 565)\end{array}$ & $\begin{array}{c}0.2 \% \\
(1 / 565)\end{array}$ & $\begin{array}{c}0 \% \\
(0 / 565)\end{array}$ \\
\hline MA & $\begin{array}{c}4.3 \% \\
(29 / 681) \\
* *, \# \#\end{array}$ & $\begin{array}{c}4.1 \% \\
(28 / 681) \\
* *, \# \#\end{array}$ & $\begin{array}{c}4.4 \% \\
(30 / 681) \\
* *, \# \#\end{array}$ & $\begin{array}{c}1.5 \% \\
(10 / 681) \\
*, \#\end{array}$ & $\begin{array}{c}1.0 \% \\
(7 / 681) \\
\#\end{array}$ \\
\hline Foxy & $\begin{array}{c}13.8 \% \\
(90 / 650) \\
* *, \# \#,++\end{array}$ & $\begin{array}{c}7.8 \% \\
(51 / 650) \\
* *, \# \#,++\end{array}$ & $\begin{array}{c}38.6 \% \\
(251 / 650) \\
* *, \# \#,++\end{array}$ & $\begin{array}{c}18.0 \% \\
(117 / 650) \\
* *, \# \#,++\end{array}$ & $\begin{array}{c}9.4 \% \\
(61 / 650) \\
* *, \# \#,++\end{array}$ \\
\hline
\end{tabular}

SAL-treated rats displayed no change. Additionally, MA treatment resulted in a shorter latency to electrographic seizures compared to the MDMA-treated rats.
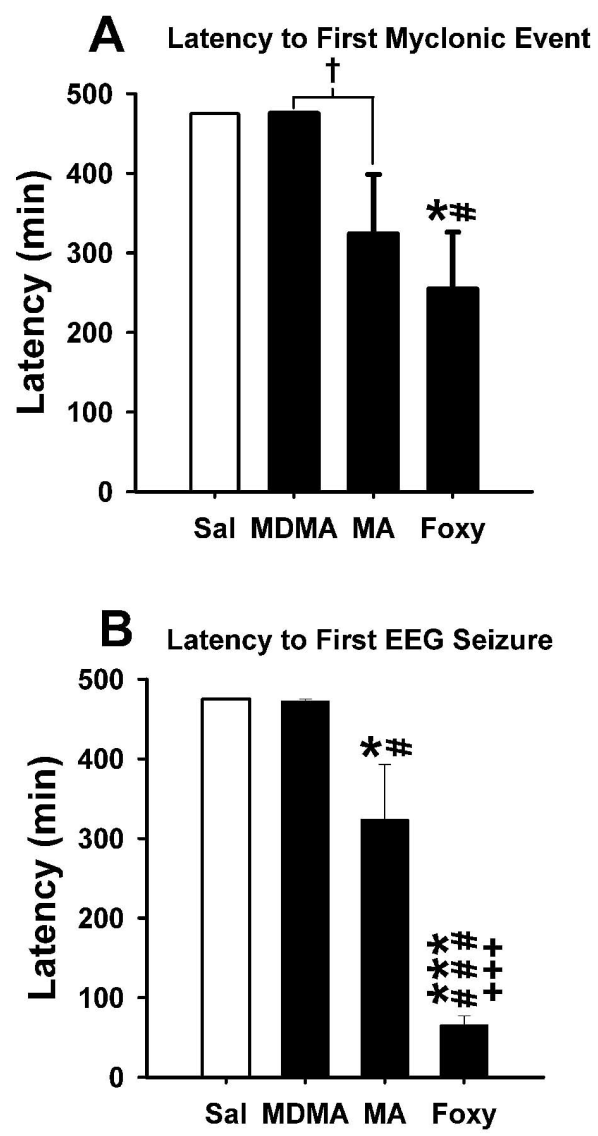

Fig. (2). Latency to First Seizure Activity. The time to onset of myoclonus (A) or abnormal electrographic activity (B) following treatment, averaged across all rats within each treatment group. ${ }^{*} \mathrm{p}$ $<0.05, * * * \mathrm{p}<0.001$ vs. SAL; $\# \mathrm{p}<0.05$, \#\#\#p <0.001 vs. MDMA; $+\mathrm{p}<0.05,+++\mathrm{p}<0.001$ vs. MA; $\uparrow \mathrm{p}<0.10$ as indicated by bars.

\section{DISCUSSION}

Seizures and abnormal EEG activity have been shown to be effects of high dose psychostimulant exposure [1-5], although it is not clear if this is the result of the drug or is secondary to confounders such as polydrug use, poor hydration, strenuous activity, inadequate nutrition, and/or genetic predisposition. This experiment determined the EEG profile in rats of three popular drugs of abuse using the exact dosing regimen shown to induce learning and memory deficits $[46,47,56,62]$ and neurochemical changes consistent with those seen in chronic users upon post mortem examination $[33,35,51,53,60,61]$. Both Foxy and MA resulted in altered EEG activity, with Foxy producing more severe effects. This is the first study to characterize the EEG activity produced by Foxy and to include all three drugs within a single experiment where direct comparisons can be made. In addition to the severe effects of Foxy, the data also show the seizure-inducing effects of MA and supports the previous findings for $\mathrm{MA}$ in rats $[12,13]$. Contrary to prediction, MDMA did not produce significant epileptiform activity.

MA affects dopamine (DA) $[64,65]$ as well as serotonin (5-HT) [66-68] and norepinephrine (NE) [64, 69]. Foxy affects the serotonergic system and most predominately the $5-\mathrm{HT}_{2 \mathrm{~A}}$ receptor [70], the 5-HT transporter [71], and 5-HT turnover [31] but does not appear to alter 5-HT, DA, or NE levels in adults rats [31]. In mice, Foxy reduces 5-HT levels in the hippocampus and prefrontal cortex [60]. MDMA affects the 5-HT system in rats $[72,73]$, non-human primates [74], and humans [75-77] with some effects upon DA [73, 78-81] and NE [82, 83]; however, it is primarily a dopaminergic agent in mice [84-86]. Given the EEG differences between drugs, i.e., lack of effects in MDMAtreated animals with inter-individual variation in susceptibility in MA-treated animals and consistent seizure activity in Foxy-treated animals, the serotonergic commonality among these drugs is unlikely to account for the EEG abnormalities observed. 
The lack of abnormal EEG activity following MDMA was surprising given the clinical literature $[6,14,21,23,24]$. However, human seizures could be related to drug impurities, the combination of drugs abused simultaneously, hyperthermia, dehydration, or combinations of these $[1,21]$. In addition, seizures may be secondary to toxicity resulting from excessive fluid intake that occurs when partiers overcompensate for the dehydration known to be associated with MDMA use. Excess fluid can produce hyponatremia which has been associated with seizure activity [3, 22, 24]. Interestingly, while we and others (in a mouse model) [28] did not observe significant spontaneous seizures, another group noted seizure activity following a single MDMA dose in mice [13]. In the latter experiment, MDMA was administered into the ventricles (i.c.v.) instead of peripherally (i.p. or s.c.). Intraventricular administration minimizes metabolism $[87,88]$ and provides a more potent route of administration. Furthermore, only one dose level of MDMA was used in the current study. While a higher dose might have induced seizure activity, we conducted the current study to determine the EEG profile following a dosing regimen of MDMA that does not increase mortality but induces long-term neurochemical and behavioral changes.

The data confirm previous findings that MA induces seizure activity as has been reported in humans [1, 2, 10, 89] and rodents $[11,13,90]$. In humans, seizures are typically transient $[1,2,25]$, although status epilepticus is reported on rare occasions [1]. MA-induced seizures are independent of route of administration or prior exposure in humans [1,3]. Our data are in accordance with the clinical features of MAinduced seizures, such that the EEG activity was brief (Types 1-2, isolated ictal spikes or runs $<10 \mathrm{~s}$ ). While mouse studies using MA or amphetamine note that these drugs produce prolonged seizures [11, 13], our data show intermittent abnormalities with $1-1.5 \%$ of the intervals showing Type 3 or 4 seizures. Bowyer and colleagues, using a single dose of amphetamine $(40 \mathrm{mg} / \mathrm{kg})$ in rats, noted that while prolonged seizure activity did not appear as it did in mice, many of the treated rats became hyperthermic (> $41.4^{\circ} \mathrm{C}$ ) and required cooling to prevent death [12]. No rat in the present study went above $40^{\circ} \mathrm{C}$ and no cooling was required. MA is known to induce hyperthermia, and the resulting thermic dysregulation has been shown to play a role in the resultant neurotoxicity [32, 33, 91]. However, experimental manipulations can spare the MA-induced thermic response while still causing deleterious effects [9295]. Thus, we cannot discount the potentially protective effect that exposure to isoflurane, administered both during the surgery as well as prior to EEG recordings, might have had upon thermal regulation, as volatile anesthetics such as isoflurane inhibit thermoregulatory control and can induce hypothermia $[96,97]$. Despite the fact that hyperthermia was not present, the literature indicates that a dose of $40 \mathrm{mg} / \mathrm{kg}$ of MA induces neurotoxicity [33, 35, 38, 40, 44, 45, 98]. However, hyperthermia may be a prerequisite to prolonged seizure activity, at least in rats, although a lack of status epilepticus does not necessarily indicate a lack of

neurotoxicity, as the aforementioned group reported blood brain barrier disruption and neurodegeneration [12]. Thus, even the brief seizures noted here could be associated with MA-induced neurotoxicity.

Limitations of the current experiment include testing only one dose and dosing regimen of each drug, testing doses of each drug that are not equimolar to one another nor equal in internal area-under-the-curve exposure levels, testing a limited range of EEG parameters, testing during a limited range of times post-treatment (including not testing for longterm recovery and/or long-term residual adverse effects). However, there was a sound basis for the dose and dose schedule used. For example, all three drugs with the exact same dose and dosing regimen used here have been shown by us and others to induce clear-cut evidence of neurotoxicity and/or behavioral and cognitive effects (see above). Further, these doses, when extrapolated to humans using allometric scaling, are similar to those found in humans among psychostimulant abusers, and are therefore, relevant. Moreover, this is the first experiment to directly compare these stimulants for epileptiform effects and therefore make a novel contribution to what is known about the drugs. Future experiments should test a range of doses and times after treatment in order to develop a more complete profile of the epileptogenic action of each drug. We acknowledge that the present data represent only the first step in such understanding but a significant step nonetheless.

\section{CONCLUSION}

This experiment compared the seizure-inducing properties of three common psychostimulants of abuse at doses known to induce neurotoxicity and cognitive deficits. The principal finding was the rapid onset and enduring seizures produced by Foxy. Little is known about the mechanism of action or pharmacodynamics of this drug, but it is clear from the present data that this drug carries significant risk of adverse effects; effects that are far more severe than from MA or MDMA in terms of seizure liability. Seizures and EEG abnormalities are associated with cognitive impairments [99-101]. Consistent with this, we and others have shown that rats given Foxy (30-80 mg/kg total) resulted in egocentric and spatial learning deficits following treatment $[31,60,61]$. Further research into how Foxy induces seizures is warranted given the present findings.

\section{AUTHORS' CONTRIBUTIONS}

DLG performed the surgery, monitored and dosed the rats, analyzed data, and wrote the manuscript. NRH and TLS monitored and dosed the rats. KDH was responsible for training in the proper surgical techniques and for analyzing the raw EEG data. MTW and CVV assisted in experimental design, analysis, and manuscript preparation.

\section{ACKNOWLEDGMENTS}

The authors would like to thank Xiaoling Liu for his technical assistance. This work was supported by NIH project grants DA006733 (CVV) and NS062756 (KDH) and training grant T32 ES007051 (CVV).

\section{CONFLICT OF INTERSEST}

None declared. 


\section{REFERENCES}

[1] Alldredge BK, Lowenstein DH, Simon RP. Seizures associated with recreational drug abuse. Neurology 1989; 39 (8): 1037-9.

[2] Kashani J, Ruha AM. Methamphetamine toxicity secondary to intravaginal body stuffing. J Toxicol Clin Toxicol 2004; 42 (7): 987-9.

[3] Zagnoni PG, Albano C. Psychostimulants and epilepsy. Epilepsia 2002; 43 (Suppl 2): 28-31.

[4] Sanchez-Ramos JR. Psychostimulants. Neurol Clin 1993; 11(3): 535-53.

[5] Ceballos NA, Bauer LO, Houston RJ. Recent EEG and ERP findings in substance abusers. Clin EEG Neurosci 2009 Apr; 40(2): $122-8$.

[6] Herning RI, Better W, Tate K, Cadet JL. Neuropsychiatric alterations in MDMA users: preliminary findings. Ann N Y Acad Sci 2005; 1053: 20-7.

[7] Newton TF, Cook IA, Kalechstein AD, et al. Quantitative EEG abnormalities in recently abstinent methamphetamine dependent individuals. Clin Neurophysiol 2003; 114(3): 410-5.

[8] Newton TF, Kalechstein AD, Hardy DJ, et al. Association between quantitative EEG and neurocognition in methamphetaminedependent volunteers. Clin Neurophysiol 2004; 115(1): 194-8.

[9] Kalechstein AD, De la Garza R 2nd, Newton TF, et al. Quantitative EEG abnormalities are associated with memory impairment in recently abstinent methamphetamine-dependent individuals. J Neuropsychiatry Clin Neurosci 2009; 21(3): 254-8.

[10] Brust JC. Seizures and substance abuse: treatment considerations. Neurology 2006; 67(12 Suppl 4): S45-8.

[11] Bowyer JF, Ali S. High doses of methamphetamine that cause disruption of the blood-brain barrier in limbic regions produce extensive neuronal degeneration in mouse hippocampus. Synapse 2006; 60(7): 521-32

[12] Bowyer JF, Thomas M, Schmued LC, Ali SF. Brain region-specific neurodegenerative profiles showing the relative importance of amphetamine dose, hyperthermia, seizures, and the blood-brain barrier. Ann N Y Acad Sci 2008; 1139: 127-39.

[13] Hanson GR, Jensen M, Johnson M, White HS. Distinct features of seizures induced by cocaine and amphetamine analogs. Eur J Pharmacol 1999; 377(2-3): 167-73.

[14] Dafters RI, Duffy F, O'Donnell PJ, Bouquet C. Level of use of 3,4methylenedioxymethamphetamine (MDMA or Ecstasy) in humans correlates with EEG power and coherence. Psychopharmacology (Berl) 1999; 145(1): 82-90.

[15] Dunkin JJ, Osato S, Leuchter AF. Relationships between EEG coherence and neuropsychological tests in dementia. Clin Electroencephalogr 1995; 26(1): 47-59.

[16] Leuchter AF, Spar JE, Walter DO, Weiner $H$. Electroencephalographic spectra and coherence in the diagnosis of Alzheimer's-type and multi-infarct dementia: a pilot study. Arch Gen Psychiatry. 1987; 44(11): 993-8

[17] Lutzenberger W. EEG alpha dynamics as viewed from EEG dimension dynamics. Int J Psychophysiol 1997; 26(1-3): 273-83.

[18] Shagass C. Electrical activity of the brain. In: Greenfield NS, Sternbach RA, Eds. Handbook of Psychophysiology. New York: Holt, RInehart, \& Winston 1972; pp. 263-328.

[19] Pollock VE, Schneider LS. Quantitative, waking EEG research on depression. Biol Psychiatry 1990; 27(7): 757-80.

[20] Schneider S, Brummer V, Mierau A, et al.Increased brain cortical activity during parabolic flights has no influence on a motor tracking task. Exp Brain Res 2008; 185(4): 571-9.

[21] Gamma A, Frei E, Lehmann D,et al. Mood state and brain electric activity in ecstasy users. Neuroreport 2000; 11(1): 157-62.

[22] Hedetoft C, Christensen HR. Amphetamine, ecstasy and cocaine. Clinical aspects of acute poisoning. Ugeskr Laeger 1999; 161(50): 6907-11.

[23] Ben-Abraham R, Szold O, Rudick V, Weinbroum AA. 'Ecstasy' intoxication: life-threatening manifestations and resuscitative measures in the intensive care setting. Eur J Emerg Med 2003; 10(4): 309-13

[24] Hartung TK, Schofield E, Short AI, et al. Hyponatraemic states following 3,4-methylenedioxymethamphetamine (MDMA, 'ecstasy') ingestion. QJM 2002; 95(7): 431-7.

[25] Olson KR, Kearney TE, Dyer JE, et al. Seizures associated with poisoning and drug overdose. Am J Emerg Med 1994; 12(3): 3925 .
[26] Lado FA, Laureta EC, Moshe SL. Seizure-induced hippocampa damage in the mature and immature brain. Epileptic Disord 2002; 4(2): 83-97.

[27] Giorgi FS, Lazzeri G, Natale G, et al. MDMA and seizures: a dangerous liaison? Ann N Y Acad Sci 2006; 1074: 357-64.

[28] Giorgi FS, Pizzanelli C, Ferrucci M, et al. Previous exposure to (+/-) 3,4-methylenedioxymethamphetamine produces long-lasting alteration in limbic brain excitability measured by electroencephalogram spectrum analysis, brain metabolism and seizure susceptibility. Neuroscience 2005; 136(1): 43-53.

[29] Kuwahara T, Nakakura T, Oda S, et al. Problems in three Japanese drug users with Human Immunodeficiency Virus infection. J Med Invest 2008; 55(1-2): 156-60.

[30] Muller AA. New drugs of abuse update: Foxy Methoxy. J Emerg Nurs 2004; 30(5): 507-8

[31] Williams MT, Herring NR, Schaefer TL, et al. Alterations in body temperature, corticosterone, and behavior following the administration of 5-methoxy-diisopropyltryptamine ('foxy') to adult rats: a new drug of abuse. Neuropsychopharmacology 2007; 32(6): 1404-20.

[32] Bowyer JF, Davies DL, Schmued L, et al. Further studies of the role of hyperthermia in methamphetamine neurotoxicity. J Pharmacol Exp Ther 1994; 268(3): 1571-80.

[33] Bowyer JF, Tank AW, Newport GD,et al. The influence of environmental temperature on the transient effects of methamphetamine on dopamine levels and dopamine release in rat striatum. J Pharmacol Exp Ther 1992; 260(2): 817-24.

[34] Broening HW, Morford LL, Vorhees CV. Interactions of dopamine D1 and D2 receptor antagonists with D-methamphetamine-induced hyperthermia and striatal dopamine and serotonin reductions. Synapse 2005; 56(2): 84-93.

[35] Broening $\mathrm{HW}, \mathrm{Pu} \mathrm{C}$, Vorhees $\mathrm{CV}$. Methamphetamine selectively damages dopaminergic innervation to the nucleus accumbens core while sparing the shell. Synapse 1997; 27(2): 153-60.

[36] Cappon GD, Broening HW, Pu C,et al. Alpha-Phenyl-N-tert-butyl nitrone attenuates methamphetamine-induced depletion of striatal dopamine without altering hyperthermia. Synapse 1996; 24(2): 173-81.

[37] Haughey HM, Brown JM, Wilkins DG,et al. Differential effects of methamphetamine on $\mathrm{Na}(+) / \mathrm{Cl}(-)$-dependent transporters. Brain Res 2000; 863(1-2): 59-65.

[38] Kokoshka JM, Fleckenstein AE, Wilkins DG, Hanson GR. Agedependent differential responses of monoaminergic systems to high doses of methamphetamine. J Neurochem 2000; 75(5): 2095-102.

[39] Metzger RR, Haughey HM, Wilkins DG,et al. Methamphetamineinduced rapid decrease in dopamine transporter function: role of dopamine and hyperthermia. J Pharmacol Exp Ther 2000; 295(3): 1077-85

[40] Pu C, Broening HW, Vorhees CV. Effect of methamphetamine on glutamate-positive neurons in the adult and developing rat somatosensory cortex. Synapse 1996; 23(4): 328-34.

[41] $\mathrm{Pu} \mathrm{C}$, Fisher JE, Cappon GD, Vorhees CV. The effects of amfonelic acid, a dopamine uptake inhibitor, on methamphetamineinduced dopaminergic terminal degeneration and astrocytic response in rat striatum. Brain Res 1994; 649(1-2): 217-24.

[42] $\mathrm{Pu} \mathrm{C}$, Vorhees CV. Protective effects of MK-801 on methamphetamine-induced depletion of dopaminergic and serotonergic terminals and striatal astrocytic response: an immunohistochemical study. Synapse 1995; 19(2): 97-104.

[43] Ugarte YV, Rau KS, Riddle EL, Hanson GR, Fleckenstein AE. Methamphetamine rapidly decreases mouse vesicular dopamine uptake: role of hyperthermia and dopamine D2 receptors. Eur J Pharmacol 2003 11; 472(3):165-71.

[44] Cappon GD, Pu C, Vorhees CV. Time-course of methamphetamine-induced neurotoxicity in rat caudate-putamen after single-dose treatment. Brain Res 2000; 863(1-2): 106-11.

[45] O'Callaghan JP, Miller DB. Neurotoxicity profiles of substituted amphetamines in the C57BL/6J mouse. J Pharmacol Exp Ther 1994; 270(2): 741-51.

[46] Herring NR, Schaefer TL, Gudelsky GA, et al.Effect of +methamphetamine on path integration learning, novel object recognition, and neurotoxicity in rats. Psychopharmacology (Berl) 2008; 199(4): 637-50.

[47] Vorhees CV, He E, Skelton MR, et al. Comparison of (+)methamphetamine, +/--Methylenedioxymethamphetamine, (+)- 
amphetamine and +/--fenfluramine in rats on egocentric learning in the Cincinnati water maze. Synapse 2011; 65: 368-78.

[48] Mordenti J, Chapell W. The use of interspecies scaling in toxicokinetics. In: Yacobi A. KJ, Batra V, Eds. Toxicokinetics in New Drug Development. New York: Pergamon Press 1989; pp. 4296

[49] Grace CE, Schaefer TL, Gudelsky GA, et al. Neonatal methamphetamine-induced corticosterone release in rats is inhibited by adrenal autotransplantation without altering the effect of the drug on hippocampal serotonin. Neurotoxicol Teratol 2010; 32(3): 356-61.

[50] Melega WP, Cho AK, Harvey D, Lacan G. Methamphetamine blood concentrations in human abusers: application to pharmacokinetic modeling. Synapse 2007; 61(4): 216-20.

[51] Shankaran M, Gudelsky GA. A neurotoxic regimen of MDMA suppresses behavioral, thermal and neurochemical responses to subsequent MDMA administration. Psychopharmacology (Berl) 1999; 147(1): 66-72.

[52] Fischer C, Hatzidimitriou G, Wlos J, Katz J, Ricaurte G. Reorganization of ascending 5-HT axon projections in animals previously exposed to the recreational drug (+/-)3,4methylenedioxymethamphetamine (MDMA, "ecstasy"). J Neurosci 1995; 15(8): 5476-85.

[53] Scanzello CR, Hatzidimitriou G, Martello AL, et al. Serotonergic recovery after (+/-)3,4-(methylenedioxy) methamphetamine injury: observations in rats. J Pharmacol Exp Ther 1993; 264(3): 1484-91.

[54] Piper BJ, Fraiman JB, Owens CB, Ali SF, Meyer JS. Dissociation of the neurochemical and behavioral toxicology of MDMA ('Ecstasy') by citalopram. Neuropsychopharmacology 2008; 33(5): 1192-205.

[55] Sumnall HR, O'Shea E, Marsden CA, Cole JC. The effects of MDMA pretreatment on the behavioural effects of other drugs of abuse in the rat elevated plus-maze test. Pharmacol Biochem Behav 2004; 77(4): 805-14.

[56] Vorhees CV, Schaefer TL, Williams MT. Developmental effects of +/-3,4-methylenedioxymethamphetamine on spatial versus path integration learning: Effects of dose distribution. Synapse 2007; 61(7): 488-99.

[57] Brennan KA, Schenk S. Initial deficit and recovery of function after MDMA preexposure in rats. Psychopharmacology (Berl) 2006; 184(2): 239-46.

[58] Sprague JE, Preston AS, Leifheit M, Woodside B. Hippocampal serotonergic damage induced by MDMA (ecstasy): effects on spatial learning. Physiol Behav 2003; 79(2): 281-7.

[59] Graham DL, Herring NR, Schaefer TL, Vorhees CV, Williams MT. Glucose and corticosterone changes in developing and adult rats following exposure to (+/-)-3,4-methylendioxymethamphetamine or 5-methoxydiisopropyltryptamine. Neurotoxicol Teratol 2010; 32(2): 152-7.

[60] Compton DM, Selinger MC, Testa EK, Larkins KD. An examination of the effects of 5-Methoxy-n, n-di(ISO)propyltryptamine hydrochloride (Foxy) on cognitive development in rats. Psychol Rep 2006; 98(3): 651-61.

[61] Compton DM, Dietrich KL, Selinger MC, Testa EK. 5-MethoxyN,N-di(iso)propyltryptamine hydrochloride (Foxy)-induced cognitive deficits in rat after exposure in adolescence. Physiol Behav 2011; 103: 203-9.

[62] Skelton MR, Schaefer TL, Herring NR, Grace CE, Vorhees CV, Williams MT. Comparison of the developmental effects of 5methoxy-N,N-diisopropyltryptamine (Foxy) to (+/-)-3,4methylenedioxymethamphetamine (ecstasy) in rats. Psychopharmacology (Berl) 2009; 204(2): 287-97.

[63] Bertram EH, Cornett JF. The evolution of a rat model of chronic spontaneous limbic seizures. Brain Res 1994; 661(1-2): 157-62.

[64] Seiden LS, Fischman MW, Schuster CR. Long-term methamphetamine induced changes in brain catecholamines in tolerant rhesus monkeys. Drug Alcohol Depend 1976; 1(3): 215-9.

[65] Wagner GC, Ricaurte GA, Seiden LS, et al. Long-lasting depletions of striatal dopamine and loss of dopamine uptake sites following repeated administration of methamphetamine. Brain Res 1980; 181(1): 151-60.

[66] Hotchkiss AJ, Gibb JW. Long-term effects of multiple doses of methamphetamine on tryptophan hydroxylase and tyrosine hydroxylase activity in rat brain. J Pharmacol Exp Ther 1980; 214(2): 257-62.
[67]

Ricaurte GA, Schuster CR, Seiden LS. Long-term effects of repeated methylamphetamine administration on dopamine and serotonin neurons in the rat brain: a regional study. Brain Res 1980; 193(1): 153-63.

[68] Friedman SD, Castaneda E, Hodge GK. Long-term monoamine depletion, differential recovery, and subtle behavioral impairment following methamphetamine-induced neurotoxicity. Pharmacol Biochem Behav 1998; 61(1): 35-44.

[69] Clemens KJ, Cornish JL, Hunt GE, McGregor IS. Repeated weekly exposure to MDMA, methamphetamine or their combination: longterm behavioural and neurochemical effects in rats. Drug Alcohol Depend 2007; 86(2-3): 183-90.

[70] Fantegrossi WE, Harrington AW, Kiessel CL, et al. Hallucinogenlike actions of 5-methoxy-N,N-diisopropyltryptamine in mice and rats. Pharmacol Biochem Behav 2006; 83(1): 122-9.

[71] Sogawa C, Sogawa N, Tagawa J, et al. 5-Methoxy-N,Ndiisopropyltryptamine (Foxy), a selective and high affinity inhibitor of serotonin transporter. Toxicol Lett 2007; 170(1): 75-82.

[72] Commins DL, Vosmer G, Virus RM, Woolverton WL, Schuster CR, Seiden LS. Biochemical and histological evidence that methylenedioxymethylamphetamine (MDMA) is toxic to neurons in the rat brain. J Pharmacol Exp Ther 1987; 241(1): 338-45.

[73] Schmidt CJ. Neurotoxicity of the psychedelic amphetamine, methylenedioxymethamphetamine. J Pharmacol Exp Ther1987; 240(1): 1-7.

[74] Ricaurte GA, Forno LS, Wilson MA, et al. (+/-)3,4-Methylenedioxymethamphetamine selectively damages central serotonergic neurons in nonhuman primates. JAMA 1988; 260(1): 51-5.

[75] Ricaurte GA, DeLanney LE, Wiener SG, et al. 5-Hydroxyindoleacetic acid in cerebrospinal fluid reflects serotonergic damage induced by 3,4-methylenedioxymethamphetamine in CNS of non-human primates. Brain Res 1988; 474(2):359-63.

[76] McCann UD, Eligulashvili V, Ricaurte GA. (+/-)3,4-Methylenedioxymethamphetamine ('Ecstasy')-induced serotonin neurotoxicity: clinical studies. Neuropsychobiology 2000; 42(1): 11-6.

[77] McCann UD, Ridenour A, Shaham Y, Ricaurte GA. Serotonin neurotoxicity after (+/-)3,4-methylenedioxymethamphetamine (MDMA; "Ecstasy"): a controlled study in humans. Neuropsychopharmacology 1994; 10(2): 129-38.

[78] Gough B, Ali SF, Slikker W, Jr., Holson RR. Acute effects of 3,4methylenedioxymethamphetamine (MDMA) on monoamines in rat caudate. Pharmacol Biochem Behav 1991; 39(3): 619-23.

[79] Nash JF, Brodkin J. Microdialysis studies on 3,4-methylenedioxymethamphetamine-induced dopamine release: effect of dopamine uptake inhibitors. J Pharmacol Exp Ther 1991; 259(2): 820-5.

[80] Able JA, Gudelsky GA, Vorhees CV, Williams MT. 3,4-Methylenedioxymethamphetamine in adult rats produces deficits in path integration and spatial reference memory. Biol Psychiatry 2006; 59(12): 1219-26.

[81] Skelton MR, Able JA, Grace CE, et al. (+/-)-3,4-Methylenedioxymethamphetamine treatment in adult rats impairs path integration learning: A comparison of single vs once per week treatment for 5 weeks. Neuropharmacology 2008; 55: 1121-50.

[82] Johnson MP, Conarty PF, Nichols DE. [3H]monoamine releasing and uptake inhibition properties of 3,4-methylenedioxymethamphetamine and p-chloroamphetamine analogues. Eur J Pharmacol 1991; 200(1): 9-16.

[83] Fitzgerald JL, Reid JJ. Effects of methylenedioxymethamphetamine on the release of monoamines from rat brain slices. Eur $\mathrm{J}$ Pharmacol 1990; 191(2): 217-20.

[84] Easton N, Marsden CA. Ecstasy: are animal data consistent between species and can they translate to humans? J Psychopharmacol 2006; 20(2): 194-210.

[85] Colado MI, O'Shea E, Green AR. Acute and long-term effects of MDMA on cerebral dopamine biochemistry and function. Psychopharmacology (Berl) 2004; 173(3-4): 249-63.

[86] Fantegrossi WE, Ciullo JR, Wakabayashi KT, et al. A comparison of the physiological, behavioral, neurochemical and microglial effects of methamphetamine and 3,4-methylenedioxymethamphetamine in the mouse. Neuroscience 2008; 151(2): 533-43.

[87] Kalant H. The pharmacology and toxicology of "ecstasy" (MDMA) and related drugs. CMAJ 2001; 165(7): 917-28.

[88] Kraemer T, Maurer HH. Toxicokinetics of amphetamines: metabolism and toxicokinetic data of designer drugs, amphetamine, 
methamphetamine, and their $\mathrm{N}$-alkyl derivatives. Ther Drug Monit 2002; 24(2): 277-89.

[89] Gray SD, Fatovich DM, McCoubrie DL, Daly FF. Amphetaminerelated presentations to an inner-city tertiary emergency department: a prospective evaluation. Med J Aust 2007; 186(7): 336-9.

[90] Bowyer JF, Robinson B, Ali S, Schmued LC. Neurotoxic-related changes in tyrosine hydroxylase, microglia, myelin, and the bloodbrain barrier in the caudate-putamen from acute methamphetamine exposure. Synapse 2008; 62(3): 193-204.

[91] Miller DB, O'Callaghan JP. Environment-, drug-and stress-induced alterations in body temperature affect the neurotoxicity of substituted amphetamines in the C57BL/6J mouse. J Pharmacol Exp Ther 1994; 270(2): 752-60.

[92] Callahan BT, Cord BJ, Yuan J, McCann UD, Ricaurte GA. Inhibitors of $\mathrm{Na}(+) / \mathrm{H}(+)$ and $\mathrm{Na}(+) / \mathrm{Ca}(2+)$ exchange potentiate methamphetamine-induced dopamine neurotoxicity: possible role of ionic dysregulation in methamphetamine neurotoxicity. J Neurochem 2001; 77(5): 1348-62.

[93] Sanchez V, Zeini M, Camarero J, et al. The nNOS inhibitor, ARR17477AR, prevents the loss of NF68 immunoreactivity induced by methamphetamine in the mouse striatum. J Neurochem 2003; 85(2): 515-24.

[94] Itzhak Y, Martin JL, Ail SF. nNOS inhibitors attenuate methamphetamine-induced dopaminergic neurotoxicity but not hyperthermia in mice. Neuroreport 2000; 11(13): 2943-6.
[95] Bowyer JF, Holson RR, Miller DB, O'Callaghan JP. Phenobarbital and dizocilpine can block methamphetamine-induced neurotoxicity in mice by mechanisms that are independent of thermoregulation. Brain Res 2001; 919(1):1 79-83.

[96] Kushikata T, Hirota K, Kotani N, Yoshida H, Kudo M, Matsuki A. Isoflurane increases norepinephrine release in the rat preoptic area and the posterior hypothalamus in vivo and in vitro: Relevance to thermoregulation during anesthesia. Neuroscience 2005; 131(1): 79-86.

[97] Sessler DI. Perioperative heat balance. Anesthesiology 2000; 92(2): 578-96.

[98] Deng X, Ladenheim B, Jayanthi S, Cadet JL. Methamphetamine administration causes death of dopaminergic neurons in the mouse olfactory bulb. Biol Psychiatry 2007; 61(11): 1235-43.

[99] Aldenkamp A, Arends J. The relative influence of epileptic EEG discharges, short nonconvulsive seizures, and type of epilepsy on cognitive function. Epilepsia 2004; 45(1): 54-63.

[100] Aldenkamp AP, Overweg J, Gutter T, et al. Effect of epilepsy, seizures and epileptiform EEG discharges on cognitive function. Acta Neurol Scand 1996; 93(4): 253-9.

[101] Aarts JH, Binnie CD, Smit AM, Wilkins AJ. Selective cognitive impairment during focal and generalized epileptiform EEG activity. Brain 1984; 107 (Pt 1): 293-308.

(C) Graham et al.; Licensee Bentham Open.

This is an open access article licensed under the terms of the Creative Commons Attribution Non-Commercial License (http://creativecommons.org/licenses/by$\mathrm{nc} / 3.0 /$ ) which permits unrestricted, non-commercial use, distribution and reproduction in any medium, provided the work is properly cited. 